\title{
Two cases of occupational leucoderma following contact with hydroquinone monomethyl ether ${ }^{1}$
}

\author{
C. P. CHIVERS \\ Imperial Chemical Industries Ltd., Mond Division, Castener Kellner Works, P.O. Box No. 9, \\ Runcorn, Cheshire
}

\begin{abstract}
Chivers, C. P. (1972). Brit. J. industr. Med., 29, 105-107. Two cases of occupational leucoderma following contact with hydroquinone monomethyl ether. In a vinylidene chloride plant two out of eight process workers handling hydroquinone monomethyl ether developed depigmentation (occupational leucoderma) of the skin of the forearms, and in one of them depigmentation of the skin of the forehead. The process operation and clinical histories are described. Leucoderma from contact with some other hydroquinone compounds is discussed.
\end{abstract}

Production of vinylidene chloride involves the use of a stabilizer, hydroquinone monomethyl ether (HMME)<smiles>COc1ccc(O)cc1</smiles>

which is introduced into the process in small batches by the plant operators, once during each eight-hour shift. HMME is a crystalline powder which has a tendency to aggregate in the supply drum. Lumps of HMME are broken up with a rod into smaller pieces causing some evolution of dust. Sufficient small pieces of HMME are ground by hand in a mortar to produce a 500-g charge which is weighed on a nearby balance. This operation results in the production of some dust.

The reaction vessel into which the powder is introduced may occasionally be under slight positive pressure and dust may, therefore, be blown about. In both the preparation and introduction of the

${ }^{1}$ Also known as paramethoxyphenol and 4-hydroxyanisole.
HMME charge a boiler suit and PVC gauntlet gloves are worn, but sometimes (as occurred in the following two cases), the shirt sleeves are rolled up under the boiler suit so that skin contamination of the forearms can easily occur.

Eight shift operators are employed; two have worked the process for more than three years, three for between two and three years, and three for less than one year. Only the two longest serving employees have been affected.

\section{Case reports}

Case 1

J.W. aged 53 years has worked for 22 years in the chemical industry, three and a half years of which have involved exposure to HMME. He gives no previous history of skin trouble. Depigmentation of the skin was first noticed by the patient about two years ago, involving the dorsum of both hands and forearms (Figs. 1 and 2 ), and has become more marked during the past 12 months. The depigmented areas become erythematous when exposed to sunlight. Application of HMME as a patch test on the forearm for one month produced slight blanching of the area of skin in contact with the powder.

\section{Case 2}

G.R. aged 38 years has worked as a painter and decorator and as a policeman, but for the last 14 years he has been employed in the chemical industry. For three 


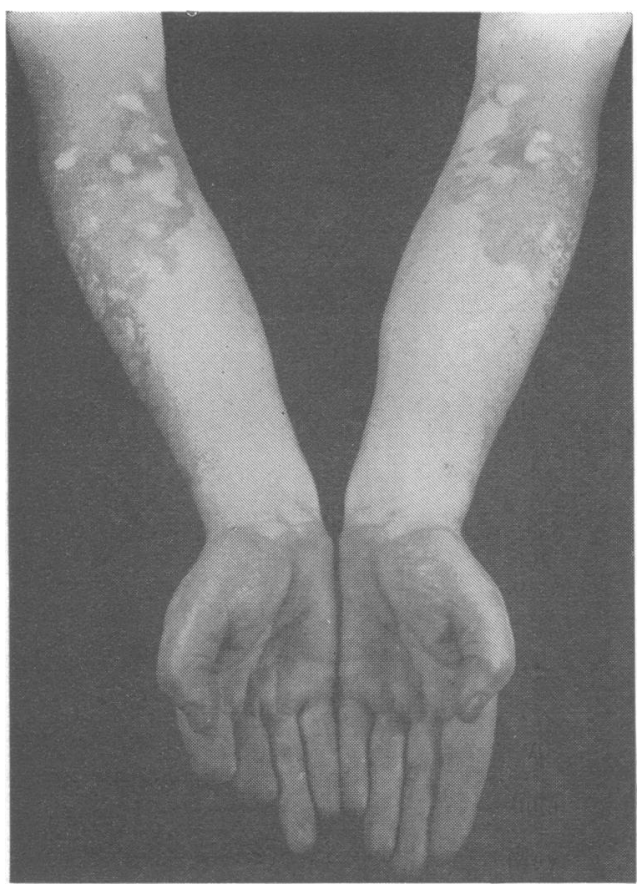

FIG. 1.

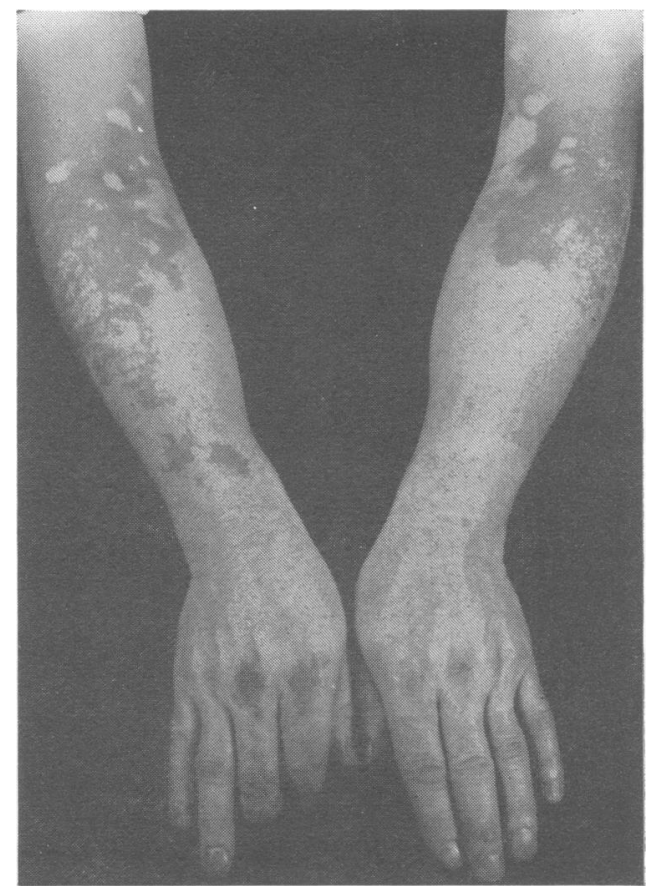

FIG. 2.

Case 1.

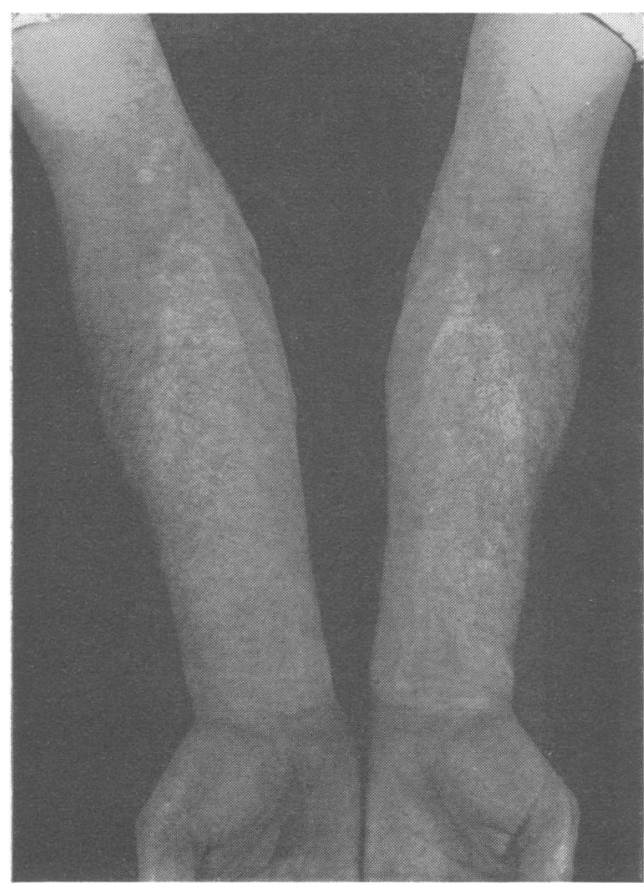

FIG. 3.

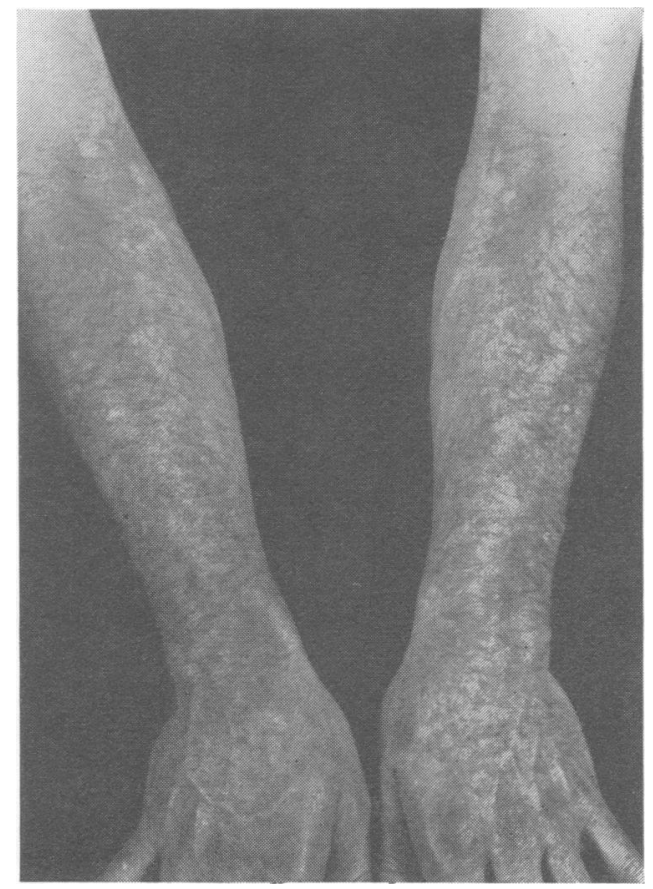

FIG. 4.

Case 2. 
years he has been exposed to HMME. Tinea pedis and occasional mild impetigo of the face have been present for 17 years, worse in the summer but quiescent at present. He was not aware of skin depigmentation until J.W. (case 1) pointed out that it was noticeable in the skin of both forearms (Figs. 3 and 4). On examination depigmentation was also found on the temples.

Dr. P. B. Mumford saw both cases and considered that had he not known the occupational history in these cases he would have considered the diagnosis to be vitiligo (i.e., idiopathic leucoderma).

\section{Discussion}

Industrial leucoderma has been widely reported in the United States, particularly among coloured people who have been in contact with hydroquinone monobenzyl ether, used as a rubber antioxidant in the production of gloves and aprons. Exceptionally it may induce leucoderma resembling vitiligo in white skin (Kalz and Schopflocher, 1965). The monobutyl ethers of hydroquinone have produced a similar clinical picture in operatives of a plant in Holland manufacturing alkyl phenols. Brun (1960) found that depigmentation occurred in the skin of experimental animals exposed to HMME and this finding was confirmed by Riley (1969) in guinea-pigs, the effect being noticeable 5 to 10 days after application of $20 \%$ HMME was begun. Repigmentation was slow but eventually complete.

No reports of HMME-induced depigmentation in man have been published, nor have cases been seen in the medical department of the firm producing the compound (personal communication).

Since the discovery of these two cases, the method of handling and introducing HMME has been reviewed and the procedure modified to reduce exposure and contact to the minimum. Alternative innocuous chemicals are being considered to replace HMME.

Having ensured that further skin contact with the material will not occur, and in view of the results of the animal experiments carried out by Riley, it is hoped that repigmentation will eventually be complete.

My thanks are due to Dr. P. B. Mumford, Manchester, with whom the cases were discussed, Dr. D. P. Duffield, Division Medical Officer, Mond Division, ICI, for assistance, and ICI Mond Division Board for permission to publish these cases.

\section{References}

Brun, R. (1960). Zur experimentellen Depigmentierung. J. Soc. Cosmet. Chem., 11, 571-580.

Kalz, F., and Schopflocher, P. (1965). Leukomelanoderma nach Anwendung einer Hydrochinonsalbe bei Zwillingen. Hautarzt, 16, 105-108.

Riley, P. A. (1969). Hydroxyanisole depigmentation: in-vivo studies. J. Path., 97, 185-191.

Received for publication March 19, 1971. 